1945. One advantage of the analysis is that it allows the immediate detection of the low long swell which travels fastest and is the first to arrive from a distant storm area. This is probably never possible by visual observation of the waves or records, because the long swell is obscured by short waves. An example showed the detection of swell, which when it first arrived was only a few inches high, with a period of 24 sec., from a depression 500 miles south-east of Newfoundland. It is hoped to make frequency analyses of waves in mid-Atlantic, for comparison with the subsequent analysis of the resulting swell in Cornwall, before the summer.

Most of the recent work described was done by the Oceanographical Group at the Admiralty Research Laboratory, Teddingtion. The paper will be published as the first number of a new series, the "Occasional Papers of the Challenger Society".

The Committee of the Challenger Society wishes to direct attention to its publication "The Science of the Sea", described in its sub-title as the Society's "Elementary Handbook of Practical Oceanography for Travellers, Sailors and Yachtsmen" (Clarendon Press, Oxford). This standard work was revised and published under the editorship of the late Dr. E. J. Allen of Plymouth in 1928, and a recent marked increase of sales of the book in the United States is thought to reflect a growing American interest in oceanography, particularly in the Pacific. Since the opportunity of producing a new edition is not likely to offer itself for some time to come and the study of the sea is of prime importance to countries of the British Commonwealth, the attention of British oceanographers, professional and amateur, is directed to this work before the stock is exhausted. The subtitle quoted above may suggest that the work is intended more particularly for amateurs, but it is of equal value to professional marine biologists. It includes chapters on the air, the water, and the sea floor, which give the physical background to other sections on plant and animal life in the varied habitats afforded by the sea. The methods of collecting, the equipment necessary, and the means of preserving and recording catches are also described.

\section{GENETICS AND TAXONOMY IN INDIA}

$\mathrm{D}$ URING the last fifteen years geneticists have been displaying an increasing interest in the problems of wild populations-with, in fact, the problems of the systematist, the ecologist and the student of evolution. The results of this activity, which are familiar from many publications, bear ample testimony to the power of genetical methods and ideas in this joint field. In taking "Genetics, Taxonomy and Ecology" as the subject of his presidential address, delivered in February 1944 to the Indian Society of Genetics and Plant Breeding (Indian J. Genetics, 4, 2 ; 1944), Dr. W. Burns has therefore been concerned less to justify such work than to consider the opportunities afforded for it by the plants of India.

Dr. Burns addresses himself especially to plant breeders, whose training in the perception of fine differences and in the genetical manipulation of cultivated plants should also enable them to add much to our knowledge of wild ones. While recognizing the value of adequate herbaria in aiding identification, and incidentally regretting the paucity of such facilitie: in India, Burns emphasizes the essential need fo observing the wild plant in its natural habitat supplemented by the experimental garden. Turning to the material which India offers, he cites many examples of natural variation which might well repaj further study. A number of these are cases of poly morphism, a phenomenon studied less in plants thar in animals so far; but attention is also directed tr cases of foreign weeds introduced into India. Th centres, directions and rates of spread of these weeds are unknown, as are the natures of the changes ir their genotypes which have occurred in response to and which have fitted them for, their new living conditions. Nor are the agencies determining the limits and changes in distribution of any of the native plants known with much certainty, though these can sometimes be related to geological boundaries A combination of botanical surveying with system. atic, genetical and cytological work, paying specia attention to clines and to the behaviour of plants at the margins of their distribution, is needed for the better understanding of all these questions.

With the growth of active interest in such problems it is well to have the attention of Indian botanists and geneticists directed to the scope afforded by the flora of their own land. The opportunities offered to them are second to none, and, if these opportunities are taken, we may be confident that the outcome will be confined in value neither to India nor to wild plants.

K. MAther.

\section{RADIO AIDS TO NAVIGATION}

\section{$T$}

HE meeting of the Institution of Electrical Engineers held in London on January 26 marked a historic occasion in so far as part of the proceedings took the form of a joint meeting with the Institute of Radio Engineers in New York, the two audiences being connected by a trans-Atlantic radiotelephone link. The American Institute was holding its first post-war winter technical meeting, at which several papers dealing with such subjects as broadcasting, navigational aids, radar, industrial electronics and radio wave propagation were being presented. The particular paper selected for the joint meeting of the two bodies was entitled "An Introduction to Hyperbolic Navigation", and was read in New York by Mr. J. A. Pierce, who has played a large part in the successful development in the United States of the radio navigational system known as Loran (LOng RAnge Navigation) [see p. 152 of this issue].

The author defined hyperbolic navigation as the use of synchronized signals, having a known velocity of propagation, transmitted from at least three fixed points, and the measurement of the relative times of arrival at a receiving point, the position of which it is required to determine. If a navigator receives simultaneously signals from two such fixed and synchronized stations, he knows that his position is somewhere along the perpendicular bisector of the line joining the transmitting stations. If one signal arrives before the other, a measurement of the timedifference identifies some other line of position on which the navigator must be. These lines of position are approximately spherical hyperbolæ.

This hyperbolic principle is at present used in at least four existing systems. Two of these use pulsemodulated signals: the Loran system referred to 